\title{
Characterization of Shielding Effectiveness of General Metallized Structure
}

\author{
Avinash $^{\text {a }}$, Mritunjay Rai ${ }^{\text {b }}$, Ravindra Kumar Yadav ${ }^{\text {* }}$ \\ ${ }^{a}$ Dept. of Electronics \& Communication Engineering, USICT, (GGSIPU), India \\ ${ }^{b, c}$ Department of Electronics \& Communication Engineering, JRE Group of Institutions, Greater Noida, India
}

\begin{abstract}
This paper describes the step-by-step procedure to design an aperture and calculation of Shielding effectiveness (SE) based on the literature reviewed and is analytically and experimentally verified using High Frequency Structural Simulator (HFSS).Also this paper includes the characterization of SE for different materials like copper, aluminum, stainless steel and nickel, which is further examined for different parameters variation effect (like dimension of wire, length of wire and frequency) is analyzed.
\end{abstract}

Index Terms: Shielding Effectiveness; HFSS; Metalized structure; Interference.

(C) 2014 Published by MECS Publisher. Selection and/or peer review under responsibility of the Research Association of Modern Education and Computer Science

\section{Introduction}

The growth of the electronic industry and the widespread use of electronic equipment in communications, computations, automations, biomedicine, space, and other purposes have led to many electromagnetic interference (EMI) problems as systems operate in close proximity. Many commercial and military applications, such as data transmission, telecommunications, wireless network systems, and satellite broadcasting, as well as radars, and diagnostic and detection systems, utilize and emit electromagnetic waves. To make an electronics devices operate satisfactorily in the presence of EMI and not to be a source of interference, shielding is required.

EM shield is essentially a barrier to regulate the transmission of the electromagnetic wave across its bulk. The term shield usually refers to a metallic enclosure that completely encloses an electronic product or a portion of that product and prevents the EM emission from an outside source to deteriorate its electronic performance.

\footnotetext{
* Corresponding author.

E-mail address: ravipusad@gmail.com
} 


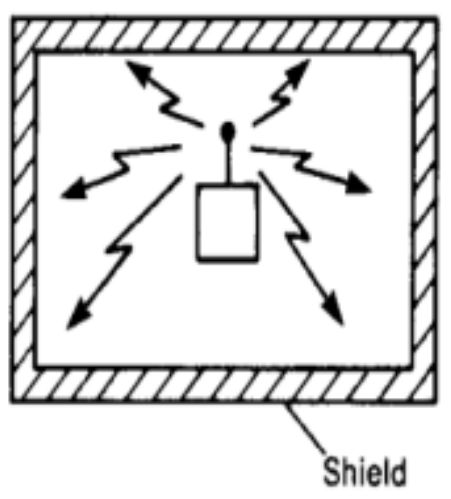

(a)

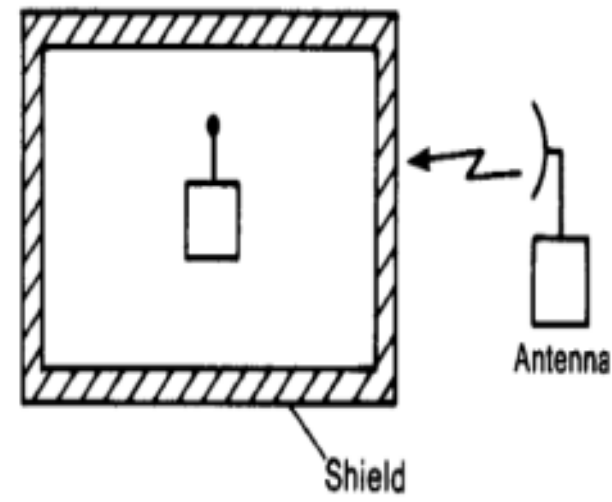

(b)

Fig.1. (a) Shield enclosure contain radiated emission, (b) Shield enclosure exclude radiated emission

In Fig.1.(a) the shield enclosed the radiated emission generated by the devices and not to be a cause of interference for the electronics devices which are outside of the boundaries and in Fig.1.(b) the electronics devices inside the shield is not interfered by the radiated emission from outside.

\section{Shielding Effectiveness}

Shielding can be specified in the terms of reduction in magnetic (and electric) field or plane-wave strength caused by shielding. The effectiveness of a shield and its resulting EMI attenuation are based on the frequency, the distance of the shield from the source, the thickness of the shield, and the shield material. The Shielding effectiveness (SE) is normally expressed in decibels $(\mathrm{dB})$ as a function of the logarithm of the ratio of the magnitude of the electric (magnetic) field that is incident on the barrier to the magnitude of the electric (magnetic) field that is transmitted through the barrier.

In terms of Electric Field,

$$
S E_{d B}=20 \log _{10}\left|\frac{E_{i}}{E_{t}}\right|
$$

In terms of Magnetic Field,

$$
\mathrm{SE}_{\mathrm{dB}}=20 \log _{10}\left|\frac{H_{i}}{H_{t}}\right|
$$

In terms of Plane Wave Field,

$$
\mathrm{SE}_{\mathrm{dB}}=10 \log _{10}\left|\frac{P_{i}}{P_{t}}\right|
$$

Where $\left(E_{i}\right.$ or $\left.H_{i}\right) P_{i}$ and $\left(E_{t}\right.$ or $\left.H_{t}\right) P_{t}$ are the power (electric or magnetic field intensity) of incident and transmitted EM waves respectively. 


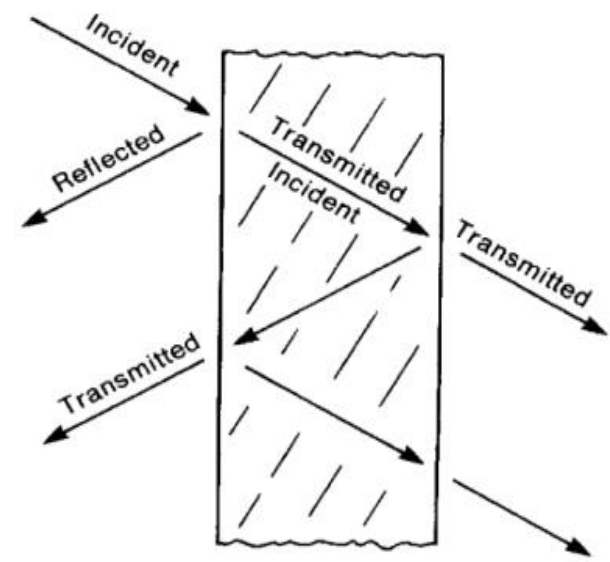

Fig.2. Basic Mechanism behind Electromagnetic Shielding

There are mainly four phenomena which governs the propagation of electromagnetic waves as its passes through the shield material. These are reflection, absorption, multiple reflection between the walls of the shield and transmission. If thicknesses of the shield are much greater than a skin depth, then multiple reflection need not to be considered. Therefore, the total shielding effectiveness of a shielding material (SE) equals the sum of the absorption factor (A), the reflection factor $(\mathrm{R})$, and the correction factor to account for multiple reflections in thin shields (M). Fig.2. shows basic mechanism of electromagnetic shielding. [1]

$$
S E_{d B}=R_{d B}+A_{d B}+M_{d B}
$$

\section{Theoretical Aspect Of Shielding Effectiveness}

\subsection{Reflection Loss}

The reflection loss is related to the relative impedance mismatch between the shield's surface and propagating wave. The magnitude of reflection loss under plane wave (far field conditions) can be expressed as: [2]

$$
R_{d B}=168+10 \log _{10}\left|\frac{\sigma}{\mu f}\right|
$$

\subsection{Absorption Loss}

As shown in Figure 2 when an electromagnetic wave passes through a medium its amplitude decreases exponentially. This decay or absorption loss occurs because currents induced in the medium produce ohmic losses and heating of the material. Therefore absorption loss can be expressed as: [2]

$$
A_{d B}=20 \log _{10} e^{\frac{t}{\delta}}
$$

\subsection{Multiple Internal Reflection Loss}

If the shield is thin, the reflected wave from the second boundary is re-reflected from the first boundary and 
returns to the second boundary to be reflected again and again as shown in Fig.2. The attenuation due these multiple internal reflections can be expressed as: [2]

$$
M_{d b}=20 \log _{10}\left(1-e^{\frac{-2 t}{\delta}}\right)
$$

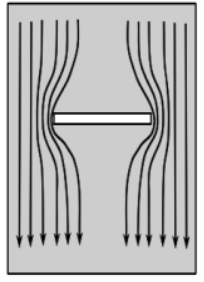

(a)

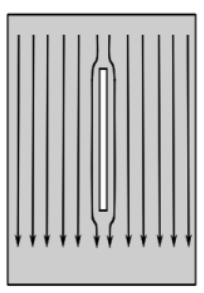

(b)

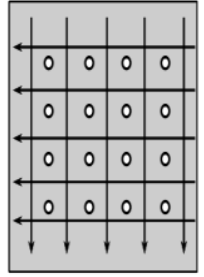

(c)

Fig.3. Qualitative effects of apertures on the surface electric current distributions

\subsection{Effect of Aperture}

When an electromagnetic wave incident on a perfectly conducting metal screen, electric currents are induced on the surface of and a reflected wave exists. If a slot is cut on the screen and path of current are perturbed SE of the screen will reduce. In Fig.3. path of the current is less perturbed in case of (c) when there is a large number of small holes on the screen and its SE will be more comparable with (a) and (b) where the slot is orthogonal and parallel to the path of current.

\subsection{Wire Mesh Structure}

Wire meshes are potentially attractive for use as electromagnetic shields because of their reduced weight per unit area compared to metallic sheets. Their physical flexibility would also make them convenient for use in "retrofit" shielding applications for large facilities [6]. The shielding behaviour of mesh screens is considered where in the individual meshes are square and of small size in comparison to the free-space wavelength. It employs an equivalent sheet-impedance dyadic operator to describe the local behaviour of the mesh, and explore a basic set of shielding problems in order to quantify the behaviour of planar shields and of shielding enclosures made of mesh. Because of its periodic structure, a mesh screen under the influence of an electromagnetic field carries a reactive field that is confined to the vicinity of the mesh surface. In the situations as considered here, where the individual meshes are electrically small, the reactive field decays away from the mesh surface as an exponential factor. The shielding effectiveness of a wire mesh screen not only depends on the frequency of operation and dimensions of the screen mesh but also on the angle of incidence of plane wave [7].

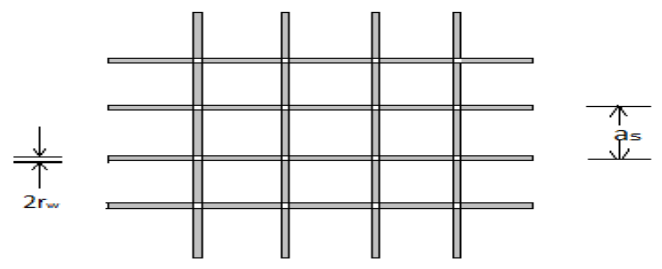

Fig.4. Geometry of wire mesh. The individual meshes are square and the wire junctions are assumed to be bonded 
Shielding Effectiveness of a planar wire meshed screen with bonded junctions can (when the mesh dimensions are small compared to the wavelength), be described through the equivalent sheet impedance of the mesh. The polarization-independent shielding effectiveness and the associated power transmission coefficient of a mesh with a square aperture of length "a" and wire radius " $r$ " can then be described as[7]:

$$
\begin{aligned}
& S E(\omega, \theta)=-10 \log _{10}\left\{\frac{1}{2}\left|T_{1}(\omega, \theta)\right|^{2}+\frac{1}{2}\left|T_{2}(\omega, \theta)\right|^{2}\right\} \\
& T_{\text {tot }}(\omega, \theta)=-S E(\omega, \theta)
\end{aligned}
$$

$T_{1}(\omega, \theta)$, and $T_{2}(\omega, \theta)$ are the transmission coefficients (for different frequencies and angles of incidence) for the polarization of $T E$ and $T M$ modes, respectively and given by [9]:

$$
\begin{aligned}
T_{1}(\omega, \theta) & =\frac{\left(\frac{2 Z_{s 1}(\omega)}{Z_{0}}\right) \cos \theta}{1+\left(\frac{2 Z_{s 1}(\omega)}{Z_{0}}\right) \cos \theta} \\
T_{2}(\omega, \theta) & =\frac{\left(\frac{2 Z_{s 2}(\omega)}{Z_{0}}\right)}{\left(\frac{2 Z_{s 2}(\omega)}{Z_{0}}\right)+\cos \theta}
\end{aligned}
$$

The angle of incidence $\theta$ is measured from the normal of the planar sheet. Besides the free-space impedance, $Z_{0}$, the comprising parts of [7].

$$
\begin{gathered}
Z_{s 1}(\omega)=Z_{w}(a)+j \omega L_{s} \\
Z_{s 2}(\omega)=Z_{s 1}-\frac{j \omega L_{s}}{2} \sin ^{2} \theta
\end{gathered}
$$

Where $Z_{S 1}$ and $Z_{S 2 v}$ are the eigenvalues of the sheet impedance operator, corresponding to the $T E$ and $T M$ mode, respectively. Also, the sheet inductance $\mathrm{L}_{\mathrm{S}}$ and the wire impedance per unit length $Z_{W}$ (approximated to its DC resistance) are given by[7]:

$$
\begin{gathered}
L_{s}=\frac{\mu_{0}}{4 \pi} \ln \left\{\left(1-e^{\frac{-2 \pi r}{a}}\right)^{-1}\right\} \\
Z_{w}=\left(\pi r^{2} \sigma\right)^{-1}
\end{gathered}
$$

The approximation of using the DC wire resistance instead of the wire impedance is motivated by the fact that there is no discernible effect of the frequencies and structures investigated here, when adding the skin effect. Thus, it becomes straight forward, for a given mesh (with square apertures), to calculate the shielding effectiveness for different situations $(\omega, \theta)$, [9]. 


\section{Research Methodology}

\subsection{DETERMINATION OF SE: Analytical Approach}

To find the SE of a material based on the formula used in which reflection loss, absorption loss and multiple reflection loss defined as:

$$
\begin{gathered}
\text { Reflection Loss, } R_{d B}=168+10 \log _{10}\left|\frac{\sigma}{\mu f}\right| \\
\text { Absorption Loss, } A_{d B}=20 \log _{10} e^{\frac{t}{\delta}}=131.4 t \sqrt{f \mu \sigma}
\end{gathered}
$$

Multiple Reflection Loss, $M_{d b}=20 \log _{10}\left(1-e^{\frac{-2 t}{\delta}}\right)$

The reflection loss is greatest at low frequencies and for high conductivity metals. Similarly, magnetic materials, $\mu_{r} \gg 1$, degrade the reflection loss. Absorption loss is increasing with increasing frequency. If the thickness of the shield $(t \ll \delta)$, then the multiple reflection loss can be neglected. These formulas applied for different materials like Copper, Nickel, Aluminium and Stainless Steel and following assumptions can be made:

\section{Experimental Approach}

\subsection{MIL-STD-285 Type Method}

The method used in this work is MIL-STD-285 type for the calculation of SE. In this method transmitter antenna and receiver antenna is located at different positions and directed towards each other and at a fix distance from each other. The transmitter is transmitting at constant power and receiver measure the transmitted power with and without test object mounted in a fix position. The SE from this method can be calculated as [15]. Fig.5. shows the ideal setup for the calculation of SE.

$$
S E_{d B}=10 \log _{10} \frac{\text { Power Received Without The Shield }}{\text { Power Received With The Shield }}
$$

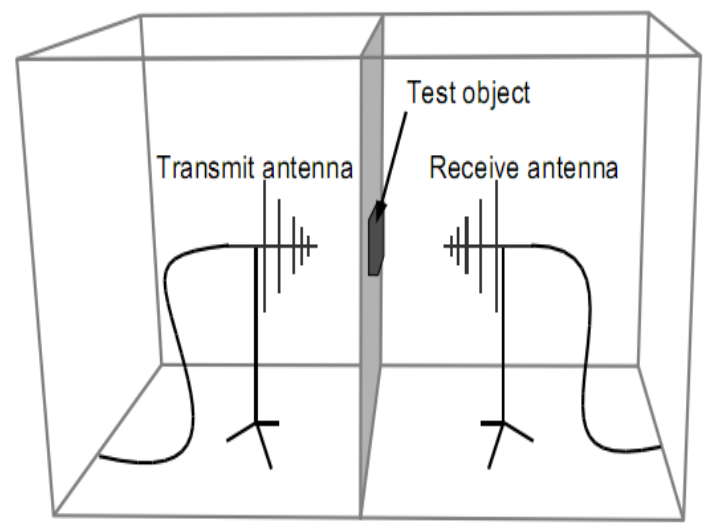

Fig.5. Shielding Effectiveness measurement according to MIL-STD-285 


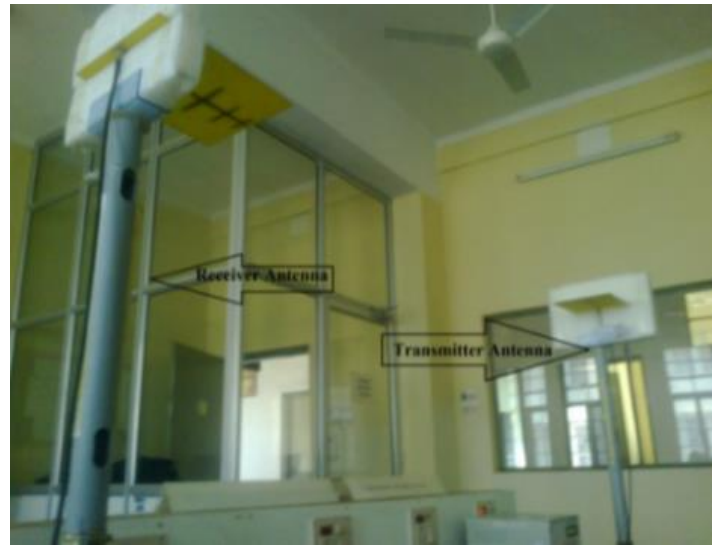

Fig.6. Experimental set up for measurement of SE without shield

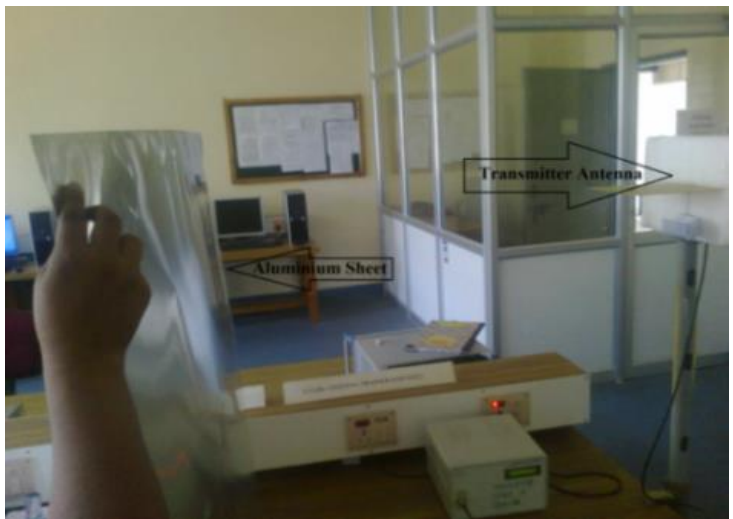

Fig.7. Experimental Set up for measurement of SE with shield

Fig.6. and Fig.7. shows the experimental setup for the SE calculation. Log periodic antenna is used as transmitter and receiver antenna. Log periodic antenna has a broad bandwidth and can be used as EMI sensor. The Frequency range of this antenna is from $750 \mathrm{MHz}$ to $1.2 \mathrm{GHz}$. A rectangular sheet of Aluminium having dimension $100 \times 100 \mathrm{~cm}$ and thickness $5 \mathrm{~mm}$ is used as a shield and SE has been calculated. In another experiment a rectangular foil of Aluminium with same dimension but different thickness of 9 micron is used as a shield and SE has been calculated. Drawbacks with the method are that measured power is dependent on the antenna placement and the reflection of the electromagnetic wave inside the experiment room. The distance between the shield and the transmitter antenna can be varied and SE at different position has been calculated.

\section{RESULTS AND DISCUSSION}

\subsection{Shield Enclosure}

To design a shield enclosure at centre frequency with $2 \mathrm{GHz}$ with SE $20 \mathrm{~dB}$ to $30 \mathrm{~dB}$. The shield enclosure has been designed for this purpose. The shield enclosure simulated without aperture and with aperture in the shield. First of all, four types of material Copper, Aluminium, Nickel and Stainless-Steel have been investigated then shield has been designed. 


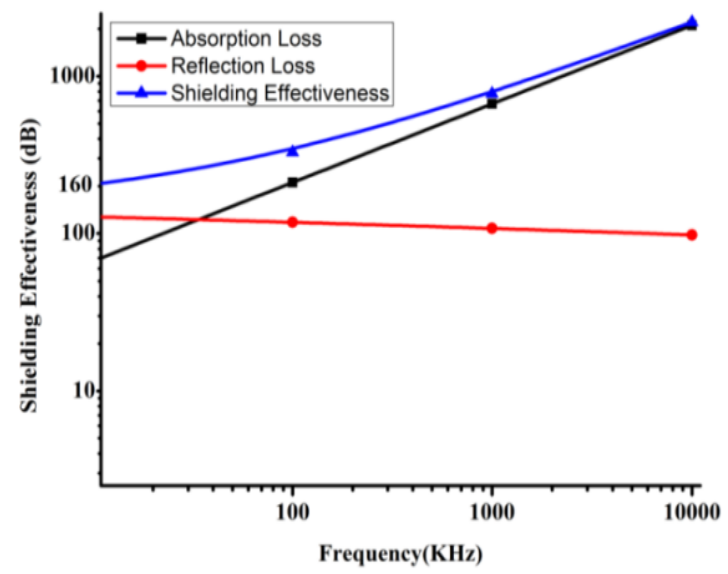

Fig.8. SE versus Frequency Plot of Copper with thickness 20 mil.

Table 1. SE of Copper with thickness 20 mil

\begin{tabular}{cccc}
\hline \multicolumn{3}{c}{ SE of (20 mil Copper) } \\
\hline $\begin{array}{c}\text { Frequency } \\
(\mathrm{KHz})\end{array}$ & $\begin{array}{c}\text { Absorption Loss } \\
(\mathrm{dB})\end{array}$ & $\begin{array}{c}\text { Reflection Loss } \\
(\mathrm{dB})\end{array}$ & $\begin{array}{c}\text { Shielding } \\
\text { Effectiveness } \\
(\mathrm{dB})\end{array}$ \\
\hline 0.01 & 2.110858285 & 158 & 160.1108583 \\
0.1 & 6.67512 & 148 & 154.67512 \\
1 & 21.10858285 & 138 & 159.1085829 \\
10 & 66.7512 & 128 & 194.7512 \\
100 & 211.0858285 & 118 & 329.0858285 \\
1000 & 667.512 & 108 & 775.512 \\
10000 & 2110.858285 & 98 & 2208.858285 \\
\hline
\end{tabular}

Table 1. shows the components of the SE for a 20 mil thickness of copper as a function of frequency from 10 $\mathrm{Hz}$ to $10 \mathrm{MHz}$. The absorption loss is dominant above $2 \mathrm{MHz}$.

These data are plotted from $10 \mathrm{~Hz}$ to only $1 \mathrm{MHz}$. Note that for this material reflection loss dominates only below $20 \mathrm{kHz}$. These data indicate that reflection loss is the primary contributor to the shielding effectiveness at low frequencies. Figure 8 shows the plot of the above table on a Log-Scale which also verified the theoretical aspect of SE.

Table 2. SE of Aluminium with thickness 20 mil

\begin{tabular}{cccc}
\hline \multicolumn{4}{c}{ SE of (20 mil Aluminium) } \\
\hline $\begin{array}{c}\text { Frequency } \\
(\mathrm{KHz})\end{array}$ & $\begin{array}{c}\text { Absorption Loss } \\
(\mathrm{dB})\end{array}$ & $\begin{array}{c}\text { Reflection Loss } \\
(\mathrm{dB})\end{array}$ & $\begin{array}{c}\text { Shielding } \\
\text { Effectiveness } \\
(\mathrm{dB})\end{array}$ \\
\hline 0.01 & 1.648633024 & 155.8532984 & 157.5019314 \\
0.1 & 5.213435382 & 145.8532984 & 151.0667337 \\
1 & 16.48633024 & 135.8532984 & 152.3396286 \\
10 & 52.13435382 & 125.8532984 & 177.9876522 \\
100 & 164.8633024 & 115.8532984 & 280.7166008 \\
1000 & 521.3435382 & 105.8532984 & 627.1968365 \\
10000 & 1648.633024 & 95.85329835 & 1744.486322 \\
\hline
\end{tabular}




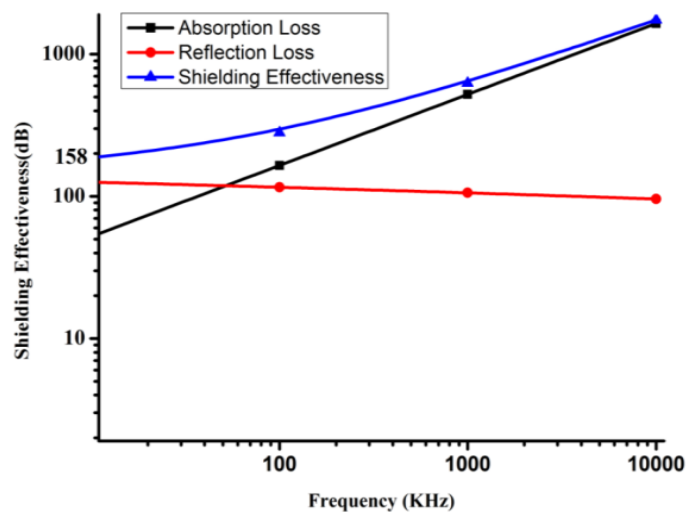

Fig.9. SE versus Frequency Plot of Aluminium with thickness 20 mil

Table 2. shows the SE for a 20 mil thickness of Aluminium as a function of frequency from $10 \mathrm{~Hz}$ to $10 \mathrm{MHz}$. At higher frequency SE increases rapidly with the comparison at lower frequencies. Figure 9 shows the plot of SE of Aluminium on a log- scale.

Table 3. SE of Stainless-Steel with thickness 20 mil

\begin{tabular}{cccc}
\hline \multicolumn{4}{c}{ SE of $(20$ mil Stainless-Steel $)$} \\
$\begin{array}{c}\text { Frequency } \\
(\mathrm{KHz})\end{array}$ & $\begin{array}{c}\text { Absorption Loss } \\
(\mathrm{dB})\end{array}$ & $\begin{array}{c}\text { Reflection Loss } \\
(\mathrm{dB})\end{array}$ & $\begin{array}{c}\text { Shielding } \\
\text { Effectiveness } \\
(\mathrm{dB})\end{array}$ \\
\hline 0.01 & 6.67512 & 114.0205999 & 120.6957199 \\
0.1 & 21.10858285 & 104.0205999 & 125.1291828 \\
1 & 66.7512 & 94.02059991 & 160.7717999 \\
10 & 211.0858285 & 84.02059991 & 295.1064285 \\
100 & 667.512 & 74.02059991 & 741.5325999 \\
1000 & 2110.858285 & 64.02059991 & 2174.878885 \\
10000 & 6675.12 & 54.02059991 & 6729.1406 \\
\hline
\end{tabular}

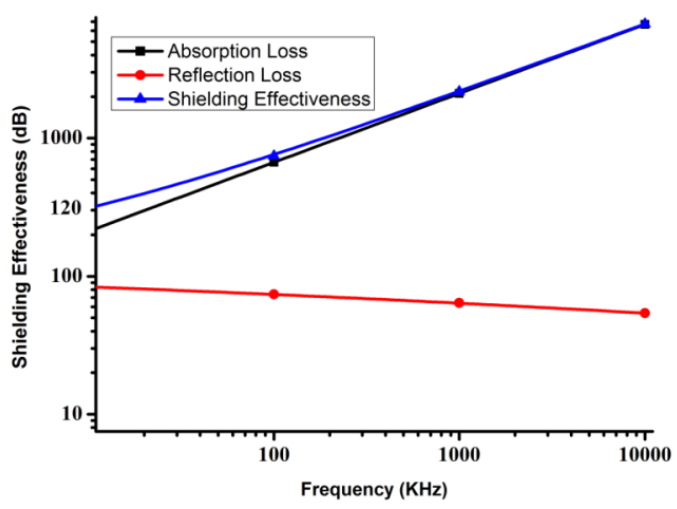

Fig.10. SE versus Frequency Plot of Stainless-Steel with thickness 20 mil 
Table 3. shows the SE for a 20 mil thickness of Stainless Steel as a function of frequency from $10 \mathrm{~Hz}$ to 10 $\mathrm{MHz}$. At higher frequency SE increases rapidly with the comparison at lower frequencies. Figure10 shows the plot of SE of Stainless Steel on a log- scale. These data indicate that reflection loss is the primary contributor to the shielding effectiveness at low frequencies for either ferrous or nonferrous shielding materials. At the higher frequencies ferrous materials increase the absorption loss and the total shielding effectiveness.

Table 4. SE of Nickel with thickness 20 mil:

\begin{tabular}{ccccc}
\hline $\begin{array}{c}\text { Frequency } \\
(\mathrm{KHz})\end{array}$ & Copper & Aluminium & Stainless Steel & Nickel \\
\hline 0.01 & 160.11086 & 157.50193 & 120.6957199 & 146.35208 \\
0.1 & 154.67512 & 151.06673 & 125.1291828 & 186.35106 \\
1 & 159.10858 & 152.33963 & 160.7717999 & 334.46173 \\
10 & 194.7512 & 177.98765 & 295.1064285 & 824.45155 \\
100 & 329.08583 & 280.7166 & 741.5325999 & 2395.5582 \\
1000 & 775.512 & 627.19684 & 2174.878885 & 7385.4564 \\
10000 & 2208.8583 & 1744.4863 & 6729.1406 & 23186.523 \\
\hline
\end{tabular}

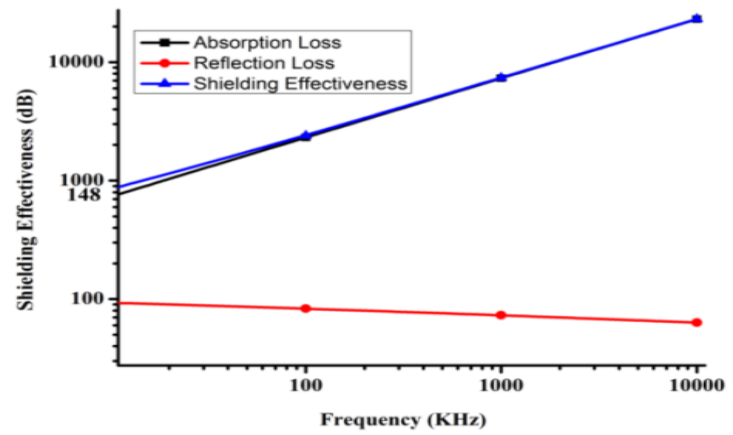

Fig.11. SE versus Frequency Plot of all four metals with thickness 20 mil

Table 4. shows the SE for a 20 mil thickness of Nickel as a function of frequency from $10 \mathrm{~Hz}$ to $10 \mathrm{MHz}$. Fig. 11. shows the plot of SE of Nickel on a log- scale. These data indicate that absorption loss is the primary contributor to the shielding effectiveness at low frequencies for either magnetic shielding material. At the higher frequencies magnetic materials increase the absorption loss and the total shielding effectiveness.

Table 5. Comparison between SE of four materials

\begin{tabular}{cccl}
\hline \multicolumn{4}{c}{ SE of (20 mil Nickel) } \\
\hline $\begin{array}{c}\text { Frequency } \\
(\mathrm{KHz})\end{array}$ & $\begin{array}{c}\text { Absorption Loss } \\
(\mathrm{dB})\end{array}$ & $\begin{array}{c}\text { Reflection Loss } \\
(\mathrm{dB})\end{array}$ & $\begin{array}{l}\text { Shielding } \\
\text { Effectiveness } \\
(\mathrm{dB})\end{array}$ \\
\hline 0.01 & 23.12329397 & 123.2287875 & 146.3520814 \\
0.1 & 73.12227596 & 113.2287875 & 186.3510634 \\
1 & 231.2329397 & 103.2287875 & 334.4617272 \\
10 & 731.2227596 & 93.22878745 & 824.4515471 \\
100 & 2312.329397 & 83.22878745 & 2395.558185 \\
1000 & 7312.227596 & 73.22878745 & 7385.456384 \\
10000 & 23123.29397 & 63.22878745 & 23186.52276 \\
\hline
\end{tabular}




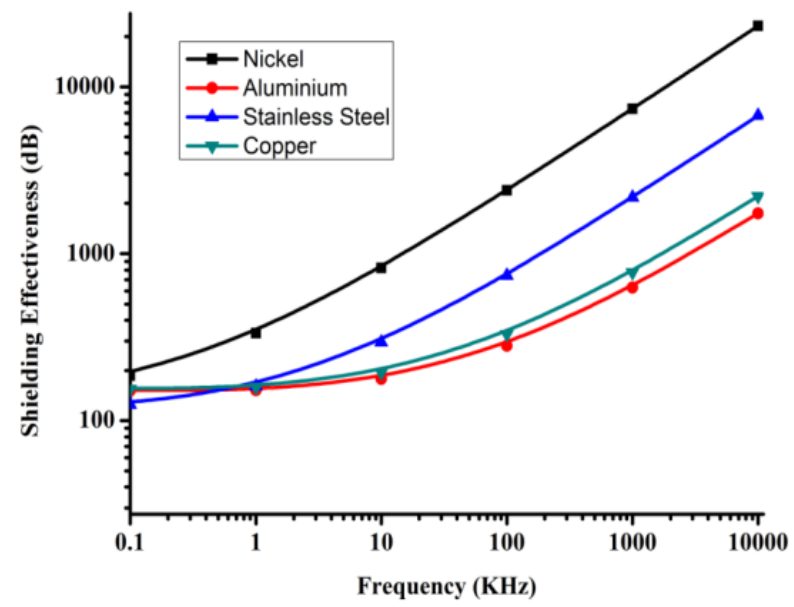

Fig.12.SE versus Frequency Plot of all four metals with thickness 20 mil

Table 5. is a comparison among all four materials which have been selected for the shielding purpose. These result shows that for same thickness of the sheet i.e. 20 mil, SE of Nickel is better than Copper, Aluminium and Stainless Steel. Although conductivity of Nickel is very low with respect to Copper and Aluminium but relative permeability of Nickel is higher than others. Figure 12 shows the plot of SE of four materials and it can be seen from the plot that Nickel exhibits higher SE.

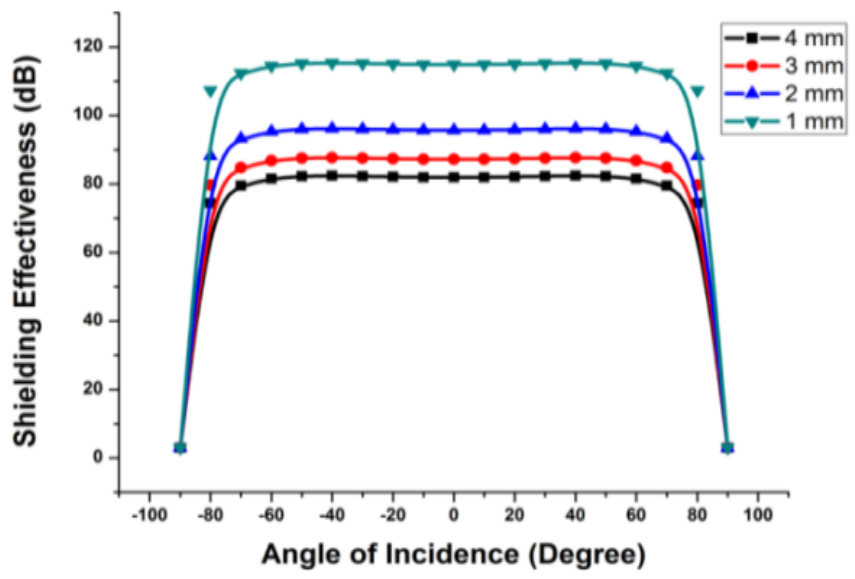

Fig.13. SE versus Angle of Incidence Plot of Copper with different mesh length

Fig.13. shows the effect of the length of a wire mesh square structure. The material used for wire mesh structure is Copper with radius $(0.03 \mathrm{~mm})$. SE increase with the decrease in length of the single unit. 
Table 6. Calculated SE from MIL-STD-285 type method

\begin{tabular}{cccc}
\hline \multirow{2}{*}{$\begin{array}{c}\text { Frequency } \\
(\mathrm{MHz})\end{array}$} & \multicolumn{2}{c}{ Power Received } & SE \\
\cline { 2 - 3 } & Without Shield & With Shield & $(\mathrm{dB})$ \\
\hline 750 & 51 & 37 & 14 \\
780 & 49.6 & 36.3 & 13.3 \\
810 & 45.1 & 36.2 & 8.9 \\
840 & 47.6 & 34.1 & 13.5 \\
870 & 36.5 & 30.9 & 5.6 \\
900 & 45.1 & 29.8 & 15.3 \\
930 & 23.4 & 28.7 & 5.3 \\
960 & 48.1 & 24.6 & 23.5 \\
990 & 51 & 43.4 & 7.6 \\
1020 & 50.1 & 42.1 & 8 \\
1050 & 54 & 40 & 14 \\
1080 & 53.6 & 45.4 & 8.2 \\
1110 & 55.3 & 43.1 & 12.2 \\
1140 & 53.1 & 42.8 & 10.3 \\
1170 & 57.2 & 41.2 & 16 \\
1200 & 59.7 & 31.8 & 27.9 \\
1230 & 57.6 & 32 & 25.6 \\
1260 & 53.9 & 41 & 12.9 \\
1290 & 56.8 & 41.6 & 15.2 \\
\hline
\end{tabular}

Table 6. shows the SE of a Aluminium Sheet with dimension $900 \mathrm{~cm}$ x $900 \mathrm{~cm}$ x $0.5 \mathrm{~cm}$. SE calculated by MIL-STD-285 type method. In this method power received measured at observation point i.e. centre point of the transmitter and receiver antenna $(0.75 \mathrm{~m})$ without the shield and with shield respectively. Obtained data plotted on a log scale and it shows SE has minimum at 930 MHz. Fig. 14.

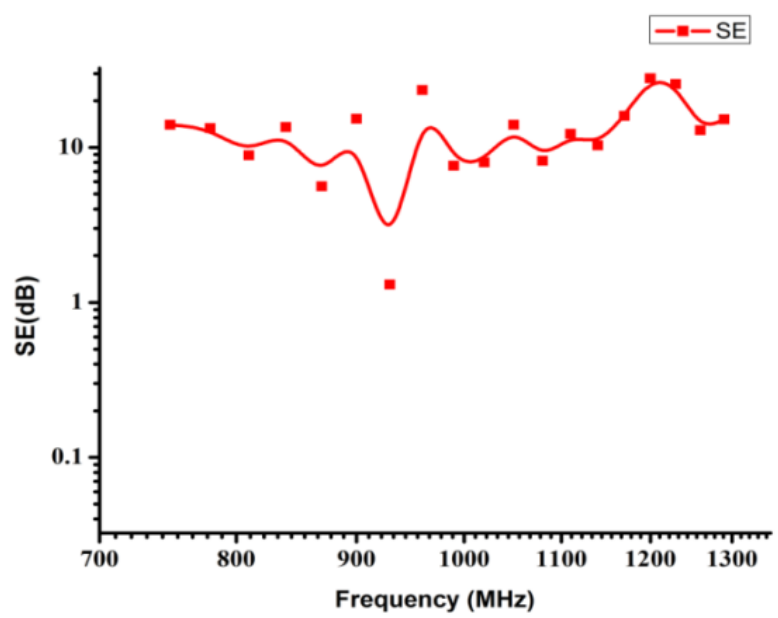

Fig.14. Measured SE versus Frequency with MIL-STD-285 method

\section{Conclusion}

Shielding effectiveness of metallic rectangular enclosure with apertures was investigated in this work. The shielding effectiveness was estimated for different polarizations, angles of incidence, frequencies and position inside the box. Following assumption can be made: 
The most common assumption of maximum field penetration for normal incidence is valid only for a single aperture on cavity. When number of apertures increases, the interaction between the radiation patterns of different apertures may result in larger enhancement of the fields for incidence angles other than the normal incidence. The polarization of the incident waves has a very strong effect upon the penetration of the fields. It was observed that the orientation of the incident electric field along a particular axis results in higher excitation of that component of the cavity electric field. The scattered fields are greatly affected by the frequency of the incident waves and resemble to those radiated by an aperture array and hence are greatly affected .The location inside the cavity has a significant affect upon the shielding effectiveness values. However, due to the modal structure of the fields, it may not be valid to assume that field intensities will be higher at points near to the apertures than at larger distances from them. We should use square and circular apertures instead of the rectangular aperture when apertures have to be used in shielding boxes. Square or circular apertures can be chosen freely according to practical situation because of the similar SE. A loss factor has been introduced to describe the damping of resonances by the contents of the enclosure.

\section{References}

[1] Clayton R. Paul, "Introduction To Electromagnetic Compatibility,” Wiley Publication.

[2] Salvatore Celozzi, Rodolfo Araneo and Giampiero Lovat, "Electromagnetic Shielding," IEEE Press, Wiley-Interscience, A JOHN WILEY \& SONS, INC., PUBLICATION.

[3] Zulfiqar Ali Khan, Charles F. Bunting and Manohar D. Deshpande, "Shielding Effectiveness of Metallic Enclosures at Oblique and Arbitrary Polarizations," IEEE Transactions on Electromagnetic Compatibility, Vol. 47, No. 1, Feb- 2005.

[4] Christopher L. Holloway,David A. Hill, John Ladbury, GalenKoepke and R. Garzia, "Shielding Effectiveness Measurements of Materials Using Nested Reverberation Chambers," IEEE Transactions on Electromagnetic Compatibility, Vol. 45, No. 2, May- 2003.

[5] M. Bahadorzadeh and A. Lotfi-Neyestanak, "A Novel and Efficient Technique for Improving Shielding Effectiveness of a Rectangular Enclosure using Optimized Aperture Load," ElektronikaIr Elektrotechnika, ISSN 1392-1215, Vol. 18, No. 10, 2012.

[6] Kendall F. Casey, "Electromagnetic Shielding Behavior of Wire Mesh Screens," IEEE Transactions on Electromagnetic Compatibility, Vol. 30, No. 3, Aug- 1998.

[7] D. Mansson and A. Ellgardt, "Comparing Analytical And Numerical Calculation of Shielding Effectiveness of Planar Metallic Meshes With Measurements in Cascaded Reverberation Chambers," Progress In Electromagnetics Research C, Vol. 31, 123-135, 2012.

[8] C Dharma Raj, M V S L Ramyasree and V Sravan Kumar, "Analysis of Wire Mesh Screen for Shielding Effectiveness in Different Frequency Ranges," International Conference on Computer, Communication and Electrical Technology - ICCCET 2011, 18th \& 19th March, 2011.

[9] D.A. Hill and J.R. Wait, "Theoretical And Numerical Studies of Wire Mesh Structure," Institute for Telecommunication Sciences Office of Telecommunications, Sensor and Simulation notes, Note 231,10Jun-1977.

[10] Urban Lundgren, "Characterization of Components and Materials for EMC Barriers," Doctoral Thesis, Dept. of Computer Science And Electrical Engineering, Lulea University of Technology, Lulea, Sweden.

[11] Luc B. Gravelle, "Shielding Effectiveness of Enclosures Predicted Via The Finite Element Method," Master Thesis, Ottawa-Carleton Institute For Electrical Engineering, University of Ottawa, Canada.

[12] Emin ÜNAL, Ahmet GÖKÇEN and Yakup KUTLU, "Shielding Effectiveness of Double Square Patches Reflecting at $900 \mathrm{MHz}$ And $1800 \mathrm{MHz} . "$

[13] D.B.O. Konditi, J.K. Makiche, H.O. Absaloms, C.O. Adika,E.K. Koechand V. M. Dharmadhikary, "Practical And Theoretical Evaluation of EMI/EMC Problems of Metallic Enclosures With Apertures," 
International Journal on "Technical and Physical Problems of Engineering” (IJTPE), Iss. 4, Vol. 2, No. 3, Sep. 2010.

[14] H. Azizi, F. Tahar Belkacem, D. Moussaouli and M. Bensetti, "Numerical Study for the Shielding Effectiveness of a Rectangular Enclosure with Apertures,"978-1-4673-0717-8/12, IEEE.

[15] Wojciech J. Krzysztofik, Robert Borowiec and Bartosz Bieda, "Some Consideration on Shielding Effectiveness Testingby Means of the Nested Reverberation Chambers," Radio engineering, Vol. 20, No. 4, December- 2011.

Mr. Avinash completed his B.E. in ECE from Shankara Institute of Technology, Jaipur and Master of Engineering (distinction) in Microwave Engineering from Birla Institute of Technology-Mesra, Ranchi. His areas of interest lie in EMI/EMC, Microstrip Filters and Antenna Design

Mr. Mritunjay Rai completed his B. Tech. in ECE from Sri Ramswaroop Memorial College of Engineering and Management, Lucknow (SRMCEM) and Master of Engineering (distinction) in Instrumentation and Control from Birla Institute of Technology-Mesra, Ranchi. His areas of interest lie in Antenna and Microwave, Image Processing,Speech Processing and Robotics \& Automation

Dr. Ravindra Kumar Yadav is an Professor in the Department of Electronics \& Communication Engineering at JRE group of Institutions, Greater Noida, U.P. Technical University Lucknow, Uttar Pradesh. He is B.E from B. N. College of Engineering, Pusad, Maharastra and M.E. from M.S. University, Baroda, Gujrat. And Ph. D in the field of antenna. He has 17 years of teaching experience in the field of microwaves and EM waves and also published the several papers to his credit in international/national journals, conferences and symposiums on antennas and fractal antennas. He has guided several B.Tech and M.Tech project

How to cite this paper: Avinash, Mritunjay Rai, Ravindra Kumar Yadav,"Characterization of Shielding Effectiveness of General Metallized Structure", IJWMT, vol.4, no.5, pp.32-45, 2014.DOI: 10.5815/ijwmt.2014.05.04 